\title{
Mestrados Profissionais em Educação: novas perspectivas da pós-graduação no cenário brasileiro
}

\section{Professional Master Programs in Education: new perspectives of postgraduate studies in the Brazilian scenario}

\author{
Nadia Hage Fialho ${ }^{1}$ \\ Tânia Maria Hetkowski ${ }^{1}$
}

\begin{abstract}
RESUMO
O processo de institucionalização da pós-graduação profissional, no Brasil, é recente e ainda inconcluso, posto inexistir, até então, doutorados profissionais implantados no país. Os mestrados profissionais constituem a primeira modalidade da pós-graduação profissional até então existente. $\mathrm{Na}$ área da Educação, o processo de institucionalização se apresenta de modo lento, por vezes, desordenado, a despeito de demonstrar períodos de intensa produção de referências legais e ou acadêmicas. Apesar disso, já anuncia algumas perspectivas para fortalecimento da base epistêmica no campo da pesquisa e da formação, ao contemplar relações entre educação superior e educação básica, mundo acadêmico e setor produtivo, setor público e setor privado, educação e formação de trabalhadores, nas mais diversas práticas sociais. Os mestrados profissionais, em face da natureza da formação e das especificidades dos trabalhos de conclusão, vêm se constituindo como um espaço importante de aplicação, de geração e de avaliação de metodologias que vão além da compreensão dos fenômenos, por incorporarem a perspectiva da aplicação, da intervenção ou do desenvolvimento.

Palavras-chave: Educação; institucionalização da pós-graduação; Mestrado Profissional em Educação.
\end{abstract}

\section{DOI: $10.1590 / 0104-4060.49135$}

1 Universidade do Estado da Bahia - Programa de Pós-Graduação Gestão e Tecnologias Aplicadas à Educação e Programa de Pós-Graduação Educação e Contemporaneidade. Salvador, Bahia, Brasil. Rua Silveira Martins, n² 2555, Cabula. CEP: 41150-000. E-mails: nadiahfialho@ gmail.come hetk@uol.com.br 


\begin{abstract}
The institutionalization of professional postgraduate studies in Brazil is a recent process and yet to be concluded, since, until now, there are no professional doctorate programs in the country. The professional master degree is the first type of professional postgraduate academic degree available. In the educational area, the institutionalization process has been slow, sometimes cluttered, despite periods of intense production of legal and/or academic references. Nevertheless, there are signs of strengthening of the epistemic base in the field of research and training, contemplating relationships between higher education and basic education, academies, the productive sector, the public sector and the private sector, education and training of workers in the most varied social practices. Professional master programs, given their own nature and the specific characteristics of final papers, have been constituted important spaces for the application, generation and evaluation of methodologies that go beyond the understanding of phenomena by incorporating the perspective of application, intervention or development.
\end{abstract}

Keywords: Education; institutionalization of professional postgraduate studies; Professional Masters in Education.

\title{
Introdução
}

Os Mestrados Profissionais em Educação (MPE) ${ }^{2}$ constituem uma modalidade de oferta da pós-graduação stricto sensu no Brasil, ou seja, são um tipo de formação que se dá para estudantes egressos da graduação, oferecida por instituições de ensino superior devidamente credenciadas pelo Ministério de Educação (MEC) e recomendada pela Coordenação de Aperfeiçoamento de Pessoal de Nível Superior (CAPES). Eles possuem características próprias que os diferenciam dos mestrados acadêmicos (MA) e, como modalidade formativa, estão previstos desde os inícios da institucionalização da pós-graduação brasileira, seja como mestrado profissional ou como doutorado profissional.

A pós-graduação profissional pretende responder pela formação de alto nível para profissionais de todas as áreas do saber não necessariamente inte-

2 Adotaremos as siglas MPE para os mestrados profissionais em Educação e MA para nos referir aos mestrados acadêmicos em Educação. Maiores detalhes sobre as especificidades de uma e outra modalidade formativa, sugerimos consultar o site da CAPES: <http://www.capes.gov.br/ acessoainformacao/perguntas-frequentes/avaliacao-da-pos-graduacao/7419-mestrado-profissional $>$. Acesso em: 15 out. 2016. 
ressados na carreira acadêmica (ênfase assumida pelos programas acadêmicos, mestrados e doutorados). O ambiente profissional ou mundo do trabalho dos pós-graduandos é importante eixo formativo dos estudantes ou acadêmicos. Especificamente na educação, destacam-se problemáticas, especialmente em relação à formação de professores (notadamente no âmbito das licenciaturas) e à gestão educacional e escolar, no âmbito dos sistemas de ensino. Assim, os MPE vão se constituindo como espaços de aplicação e geração de processos formativos e de investigação, de natureza teórica e metodológica, que se abrem perante o extenso campo de atuação de professores, gestores e profissionais da educação, fortalecidos pela aproximação entre a educação superior e a educação básica.

$\mathrm{Na}$ área da Educação, a implantação da pós-graduação profissional é recente (menos de dez anos) e até então se restringe ao mestrado ${ }^{3}$, de modo que a implantação do doutorado profissional se constitui uma das suas perspectivas; outras vão sendo anunciadas por sua inserção no campo da pesquisa aplicada, da pesquisa e desenvolvimento, das chamadas metodologias ativas e maior aproximação entre universidades, sistemas de ensino e escolas. Esse cenário modifica o contexto anterior, no qual a pós-graduação stricto sensu em educação detinha um perfil essencialmente acadêmico, voltado à formação de docentes para a carreira universitária. Os MPE dão início a um processo que passa a contemplar a educação básica e a formação de profissionais da educação dos sistemas de ensino e de outros ramos profissionais, do setor público e privado, não necessariamente acadêmico. Veremos, a seguir, como vem acontecendo a sua institucionalização no Brasil.

O Parecer $n^{\circ}$ 977/1965, conhecido como Parecer Sucupira (BRASIL, 1965), que regulamentou a pós-graduação brasileira, introduziu a pós-graduação profissional stricto sensu (mestrado e doutorado) ${ }^{4}$. A Portaria n ${ }^{\circ} 80 / 1998$ (CAPES, 1998) marcou o reconhecimento dos mestrados profissionais. No âmbito das associações científicas e fóruns ${ }^{5}$, à Associação Nacional de Pós-Graduação e Pesquisa em Educação (ANPED) e Fórum de Pró-Reitores de Pós-Graduação e Pesquisa em Educação (FORPRED) somaram-se o Fórum Nacional dos Mestrados Profissionais (FORPROF), criado em 2006, e o Fórum Nacional dos Mestrados Profissionais em Educação (FOMPE), em 2014. Na área da

3 Os primeiros programas profissionais nasceram em instituições públicas, na Universidade Federal de Juiz de Fora (UFJF), em 2009 (Gestão e Avaliação em Educação Pública) e na Universidade do Estado da Bahia (UNEB), em 2011 (Gestão e Tecnologias Aplicadas à Educação).

4 Conforme o Parecer, a pós-graduação compreende a formação lato sensu (que abrange os níveis de aperfeiçoamento e de especialização) e a stricto sensu (mestrados e doutorado), acadêmica e profissional.

5 Disponíveis nos sites: <www.anped.org.br;http://www.anped.org.br/forpred>; <http:// www.foprof.org.br>; <http://www.fompe.caedufjf.net>. Acesso em: 06 set. 2016. 
Educação, o primeiro programa stricto sensu na modalidade de MPE se deu em 2009. A primeira indicação formal de membro da Comissão de área da Educação assumida pela CAPES para os assuntos relativos aos MPE ocorreu na reunião de 05 a 07 de março de $2012^{6}$.

É possível considerar que os elementos acima mencionados enfeixam as condições de institucionalidade dos programas profissionais de pós-graduação stricto sensu em Educação, no Brasil: o Parecer Sucupira constitui a base legal da pós-graduação profissional; a Portaria $n^{\circ}$ 80/1998 é referência de ordem legal específica; a implantação do primeiro programa de pós-graduação em educação (MPE) é o elemento que consubstancia, concretamente, a implantação da nova modalidade formativa; as associações e fóruns conformam o campo de veiculação dos conhecimentos e discussão das políticas para a Educação; e a designação de membro de Comissão de Área da Educação representa o braço institucional da CAPES, para os assuntos correspondentes aos MPE.

Entretanto, tais elementos não são suficientes para assegurar que a institucionalização produza resultados no sentido da qualificação do sistema educacional do país se não estiver acompanhada de uma radical mudança de postura a respeito das problemáticas que continuam sendo assinaladas pelos pesquisadores da área da Educação. Não se pode desprezar o fato de que o Brasil se encontra diante de dois grandes desafios: o Plano Nacional de Educação (PNE) 2014-2024 (e, consequentemente, o Sistema Nacional de Educação) (SNE, 2014) - e o Plano Nacional de Pós-Graduação (PNPG) 2011-2020 (PNPG, 2010). O contexto atual expõe a complexidade dos problemas, a persistência de baixos indicadores e o lento avanço nos resultados, como se comprovou, com a divulgação, pelo Instituto Nacional de Estudos e Pesquisas Educacionais Anísio Teixeira (INEP), do Índice de Desenvolvimento da Educação Básica $(\text { IDEB })^{7}$, de 2015: a meta para as séries iniciais do ensino fundamental foi de $74,7 \%$ das redes municipais (que detém $82,5 \%$ das matrículas públicas); para os anos finais do ensino fundamental, apesar do avanço verificado, a meta não foi alcançada; e, no ensino médio não houve mudança, mantendo-se estagnada desde 2011. (INEP, 2016).

6 Relatório da Reunião de Coordenadores dos Programas de Pós-Graduação da área de Educação, 05 a 07 de Março/2012, Brasília: Capes. Disponível em: <http://www.capes.gov.br/ images/stories/download/avaliacao/Relatorio_Reuniao_Coordenadores_Educacao.pdf $>$. Acesso em: 06 ago. 2016.

7 Maiores aprofundamentos, consultar as sinopses estatísticas da educação básica. Disponível em $<$ http://portal.inep.gov.br/basica-censo-escolar-sinopse-sinopse $>$ e Resumo Técnico: resultados do Índice de Desenvolvimento da Educação Básica 2005-2015. Inep, Setembro, 2016. Disponível em: <http://download.inep.gov.br/educacao_basica/portal_ideb/planilhas_para_download/2015/ resumo_tecnico_ideb_2005-2015.pdf >. Acesso em: 12 set. 2016. 
O panorama não é simples; manifesta-se sobre extensa base territorial (5.570 municípios), cujas realidades regionais e locais - afetadas também pelos cenários mundial e nacional - expressam, nas suas específicas configurações, outros desafios. Tais problemáticas se apresentam de modo heterogêneo e desigual, nas diferentes regiões do Brasil, requerendo abordagens que contemplem singularidades da cultura educacional e escolar das respectivas comunidades.

Diante desse panorama, acompanhamos as reflexões de pesquisadores da área da Educação, a exemplo de Luciano Mendes de Faria Filho (2013):

No seu conjunto, o novo PNPG proposto e aprovado reafirma, sem dúvida, a importância da educação básica para o desenvolvimento social, econômico e tecnológico do país, reconhecendo também que não dá mais para sustentar um Sistema Nacional de Pós-Graduação de primeiro mundo com uma escola básica em que a valorização do professor e as condições de trabalho aproximam-se do quarto mundo.

Por outro lado, para o PNPG é imperativo que as outras áreas - além da área da educação - se preocupem com a educação básica. Aliás, há que se reconhecer que depois que a Capes passou a dispor de mais recursos para a educação básica, várias áreas, instituições e pesquisadores passaram a propor ações em educação. O problema, parece-me, é que muitas dessas ações, assim como o próprio texto do PNPG, não tomam o conhecimento produzido nos programas em educação e em ensino de ciências e matemática importante como ferramentas para atuarem. (FARIA FILHO, 2013, p. 291).

Esse é, pois, o cenário pelo qual caminhamos, com o objetivo de identificar, nos processos de institucionalização da pós-graduação profissional stricto sensu em Educação, a emergência de novas perspectivas no cenário brasileiro.

\section{Pós-graduação profissional strictu sensu e Educação}

Para iniciar, destacamos, do ano de 1995, marcos importantes do processo de institucionalização dos programas profissionais: o primeiro diz respeito ao registro, em informativo da CAPES sobre "[...] o surgimento de novas demandas de formação de profissionais de alto nível que não irão, necessariamente, atuar na vida acadêmica". (NEVES, 2005, p. 16). Outro, foi o documento "Mestrado no Brasil: a situação e uma nova perspectiva". (REVISTA BRASILEIRA DE 
PÓS-GRADUAÇÃO, 2005), que abordou o “[...] surgimento de programas de mestrado com características diferentes dos existentes no sistema de pós-graduação do País [...] diferenças que se manifestam na orientação dos currículos, na composição do corpo docente e discente, nas formas de financiamento e nos arranjos institucionais" (p. 139); e "[...] a necessidade e conveniência de implementar programas de mestrado dirigidos à formação profissional, bem como a possibilidade de acolhê-los de maneira natural no sistema de pós-graduação". (p. 144). Ainda em 1995, a CAPES aprovou o "Programa de Flexibilização do Modelo de Pós-Graduação Senso Estrito em Nível de Mestrado1995” (REVISTA BRASILEIRA DE PÓS-GRADUAÇÃO, 2005), que deu origem à Portaria $n^{\circ}$ 47/1995 (CAPES, 1995), determinando a implantação de procedimentos apropriados à recomendação, acompanhamento e avaliação de cursos de mestrado dirigidos à formação profissional. A citada Portaria $n^{\circ}$ 47/1995 foi revogada pela Portaria $n^{0} 80 / 1998$ (CAPES, 1998), consagrada como a que conferiu "reconhecimento dos mestrados profissionais". A partir de então, com maior ou menor ênfase, afirmava-se a necessidade e a singularidade da formação pós-graduada profissional. Em reunião realizada em 15 de setembro de 1999, o Conselho Técnico-Científico (CTC)/CAPES aprovou documento relativo aos pressupostos para avaliação de projetos de mestrado profissional (REVISTA BRASILEIRA DE PÓS-GRADUAÇÃO, 2005, p. 126), cuja nova versão foi editada em 2002, sob o título: "Parâmetros para análise de projetos de mestrado profissional 2002” (REVISTA BRASILEIRA DE PÓS-GRADUAÇÃO, 2005, p. 156-161). Em 2001, o documento "Capes - a necessidade de desenvolvimento da pós-graduação profissional e o ajustamento do sistema de avaliação às características desse segmento" recomendava "[...] que a pós-graduação brasileira deve abranger duas vertentes de formação igualmente importantes para o desenvolvimento do País" (INFOCAPES, 2002, p. 52), a acadêmica e a profissional. Mas, reconhecia-se também a existência de obstáculos que precisavam ser superados tanto com relação à forma como a CAPES procedia na avaliação das propostas de cursos profissionais, quanto às reações de parte da comunidade acadêmica à formação profissional da pós-graduação stricto sensu. Compreendia-se que, a despeito do estímulo e das orientações contidas nos documentos e normativas da CAPES, não se percebiam avanços no sistema, o que foi atribuído a resistências de áreas do conhecimento (Ex.: Direito, Medicina, Educação...) e a dificuldades, da própria CAPES, em definir questões relativas às diferenciações entre mestrados acadêmicos e mestrados profissionais (avaliação, modalidades dos trabalhos de conclusão de curso, entre outros), como

8 Registre-se que a despeito da menção, no caput, a mestrados profissionais, o texto mantém a denominação "mestrado profissionalizante". 
relatado em estudos sobre os temas. (BARROS; VALENTIM; MELO, 2005; HOSTINS, 2006, entre outros).

Vale ressaltar, entretanto, que as questões levantadas sobre a avaliação não se restringiam à institucionalização de mestrados profissionais; abarcavam outros temas relativos à avaliação de programas de pós-graduação, que mereceram a reflexão de importantes pesquisadores da Educação (MORAES, 1999, 2002; GATTI et al., 2003; MOREIRA; HORTALE; HARTZ, 2004; SPAGNOLO; SOUZA, 2004; HORTA; MORAES, 2005; KUENZER; MORAES, 2005; FÁVERO, 2012; WASSEM, 2015, entre outros). Vale a pena mencionar duas referências que expressam, sinteticamente, o posicionamento dos pesquisadores da área da Educação:

A impressão geral que resta, no fim desta análise, é que a avaliação da Capes não necessita de reestruturação em suas linhas mestras. Precisa, sim, ser mais leve e mais amigável. Também deve tentar abrir-se a aspectos novos e definir melhor ideias ainda não muito bem assimiladas pela Academia. Não são grandes alterações, mas já podem mudar a cara da avaliação da Capes: mais flexível, mais aberta e mais participativa, sem perder sua preocupação central com a qualidade e a pesquisa. (SPAGNOLO; SOUZA, 2004, p. 34).

O processo avaliativo provocou polêmicas no meio acadêmico e causou - e ainda causa - desconforto no universo da pós-graduação brasileira, não obstante ser absolutamente consensual, mesmo entre seus mais ferrenhos críticos, a importância da avaliação, particularmente a efetivada por pares, tal como procede a CAPES. (HORTA; MORAES, 2005, p. 95).

Dispondo sobre os mestrados profissionais, portanto, diversas portarias ${ }^{9}$ foram editadas e revogadas, encontrando-se, atualmente em vigência, a Por-

9 Portaria Normativa $n^{\circ} 17$, de 28 de dezembro de 2009, que revogou a Portaria $n^{\circ} 7$, de 22 de junho de 2009. Disponível em: <http://www.capes.gov.br/images/stories/download/avaliacao/ avaliacao-n/Portaria-MEC-17-2009.pdf >; <https://www.capes.gov.br/images/stories/download/ legislacao/Revogada-Portaria-Normativa-n_7-22-de-junho-2009-Mestrado-Profissional.pdf>; Portaria $\mathrm{n}^{\mathrm{o}}$ 174, de 31 de dezembro de 2014, revogadas as Portarias $\mathrm{n}^{\mathrm{o}} 1$, de 04 de janeiro de 2012, e 02, de 05 de janeiro de 2012. Disponível em: <https:/www.capes.gov.br/images/stories/download/ legislacao/PORTARIA-N-174-DE-30-12-2014.pdf>. Foram revogadas as Portarias $\mathrm{n}^{\circ} 174$, de 30 de dezembro de 2014; e $\mathrm{n}^{\circ}$ 50, de 22 de abril de 2015. Disponível em: <http://www.capes.gov.br/ images/stories/download/legislacao/06062016-PORTARIA-N-8-De-3-DE-JUNHO-DE-2016.pdf>. Acesso em: 06 set. 2016. 
taria ${ }^{\circ}$ 81/2016. (CAPES, 2016). E documentos do FORPRED, FORPROF e FOMPE, elaborados por seus pesquisadores, subsidiaram debates e encaminhamentos relativos à institucionalização dos MPE.

\section{Pós-graduação profissional em Educação: perspectivas em destaque}

Os MPE são, eles mesmos, uma nova perspectiva, não apenas no que eles podem promover, mas no próprio processo que implicou concebê-los, dar-lhes forma, desenhar arranjos institucionais. Trata-se de um processo de dinâmica social, que implica instituir algo que não está dado, por vezes em meio a confrontos com o já existente, num contexto de debates, tensões, retrocessos, polêmicas, revisões, aprofundamentos e avanços. Dessa forma, compreendemos que, no cenário brasileiro, no âmbito dos MPE, alguns conjuntos de temáticas se fizeram presentes, ora anunciando novas perspectivas (a exemplo dos encaminhamentos relativos à atualização da Ficha de Avaliação e da reafirmação do compromisso com a educação básica), ora reiterando princípios e conquistas (como ilustra a defesa do rigor da avaliação, da composição do quadro docente formado por doutores e da pesquisa como fundamento de todo o processo formativo).

Nesse sentido, vem se processando a (re)adequação do Documento de Área e da Ficha de Avaliação dos MPE ${ }^{10}$, com participação do FOMPE, tendo em vista a primeira Avaliação Quadrienal 2013-2016; os MPE reiteram a importância do rigor na Ficha de Avaliação correspondente, incluindo itens que exigem especificações para a descrição e as produções de natureza acadêmica e profissional, considerando que os cursos nessa modalidade devem ter consistente base epistêmica e detalhamento das ações práticas; disponibilizam apoio à Comissão de Avaliação para realizar análise minuciosa e de qualidade dos cursos, observando o rigor do trabalho científico; e fazem proposições para itens da Ficha de Avaliação, a exemplo da ampliação da área de atuação dos Programas, em virtude da multidisciplinaridade dos MPE, da composição do corpo docente permanente com titulação mínima de doutorado; inclusão de projetos em cooperação com a própria universidade de lotação, com secretarias de educação e com organizações não governamentais; especificação dos critérios de avaliação dos trabalhos de conclusão dos mestrandos, para também propiciar melhor

10 Proposta para a nova Ficha de Avaliação dos MPE foi encaminhada à CAPES em 30 de novembro de 2015, para análise da Coordenação, visando proporcionar avanços na avaliação quadrienal 2013-2016, contemplando as especificidades dos MPE. 
entendimento acerca dos formatos constantes da(s) normativa(s); equilíbrio dos pesos e percentuais relativos à técnica e geração de produtos, para garantir consistência epistêmica e prática, bem como valorização da produção; adoção do percentual de $30 \%$ na produção técnica em face da natureza profissional do MPE e inserção em redes de educação; adoção do percentual de $20 \%$ na distribuição da produção científica e técnica do corpo docente, considerando a relevância da produção técnica para os MPE; alinhamento das noções sobre produção técnica e científica, proposta do programa e plataforma Sucupira ${ }^{11}$; explicitação dos impactos (social, educacional, econômico, tecnológico, entre outros), na proposta do curso, dada sua importância para os MPE; esclarecimento acerca da integração e cooperação com outros programas, uma vez que o FOMPE cumpre este objetivo, mas não tem o reconhecimento por outras instâncias nacionais; inclusão da integração e cooperação interinstitucional internacional; e inclusão, na Ficha de Avaliação dos MPE, de item da Ficha de Avaliação dos MA que trata da inserção acadêmica do corpo docente (participação em atividades e eventos científicos em nível nacional, regional e internacional), por elevada importância, também para os MPE, da troca de experiências e inserção social, para além dos espaços profissionais e atuação.

Esse primeiro conjunto temático indica que a pós-graduação em Educação pode estar prestes a consolidar processos com grande potencial de fortalecimento da sua base epistêmica, ao contemplar relações entre educação superior e educação básica, mundo acadêmico e setor produtivo, setor público e setor privado, educação e formação de trabalhadores, das mais diversas práticas sociais. É nessa perspectiva que a educação não se reduz a uma dimensão instrumental e nem se coloca como promotora de processos adaptativos, como se as mudanças sociais e econômicas estivessem "fora" dos sujeitos, bastando ajustá-los aos novos contextos. Todo processo formativo, qualquer que seja o campo de atuação profissional - inclusive setores não acadêmicos - implica questões da ordem do pedagógico. Os MPE, por lidar com processos formativos, em quaisquer relações, sejam elas no âmbito do público ou do privado, encontram, no espaço acadêmico do MPE, amplas possibilidades de construção e aprofundamento.

Um segundo conjunto temático diz respeito às mudanças que já se verificam no panorama da pós-graduação, de onde emerge uma nova configuração da oferta, vagas, áreas de conhecimento, natureza jurídica, dependência administrativa, articulação com sistemas de ensino, inserção dos egressos, abrangência territorial, zonas de concentração e de escassez na distribuição das competências acadêmicas e dos acréscimos de técnicas e informações. (SANTOS; SILVEIRA,

11 A Plataforma Sucupira é uma ferramenta de gestão on-line do sistema nacional de pós-graduação no Brasil. 
2000, 2001). Um panorama que pode sinalizar o risco de acentuar o hiato entre umas e outras, agravando desequilíbrios regionais e desigualdades sociais, assim como a possibilidade para indicar perspectivas, melhor estruturadas, para a expansão da pós-graduação. A área de Educação possui, atualmente, 44 MPE num universo de 172 Programas de pós-graduação, correspondentes a 246 cursos (128 mestrados acadêmicos e 74 doutorados), conforme última avaliação divulgada pela Plataforma Sucupira. (CAPES, 2016). A sua distribuição no território é potente indicador de análise das questões sociais, econômicas e educacionais. São 20 MPE na região Sudeste, nos estados de São Paulo (12), Minas Gerais (7) e Rio de Janeiro (1); 11 MPE na região Nordeste, nos estados da Bahia (6) Pernambuco (3) e Paraíba (2); 8 MPE na região Sul, nos estados do Rio Grande do Sul (5), Paraná (2) e Santa Catarina (1); 2 MPE na região Centro-Oeste, no estado de Mato Grosso do Sul (1) e no Distrito Federal (1); e 2 MPE na região Norte, nos estados de Roraima (1) e Tocantins (1). Essa distribuição reflete o contexto de desequilíbrios regionais e desigualdades sociais do país, no qual se situam questões como equidade, qualidade da oferta, garantia do acesso e permanência com sucesso de todos os que buscam esta formação; e cuja expansão implica, necessariamente, a implantação dos doutorados profissionais, para formação de novos mestres, gerando maior inserção nos sistemas de ensino e outros ambientes profissionais.

Um terceiro conjunto temático diz respeito ao foco na formação profissional, na articulação entre os níveis educacionais e com educação básica, um dos seus mais relevantes elementos inovadores. Trata-se de uma mudança de grande vulto, que presumimos convergente com o PNPG 2011-2020 ao explicitar a educação básica como "um assunto estratégico". (PLANO NACIONAL DE PÓS-GRADUAÇÃO, 2010, p. 164). No contexto mundial, muitas foram as transformações que, na virada do século XX e inícios do século XXI, incidiram sobre a cultura escolar, as escolas, os sistemas de ensino, os valores, os modos de pensar e de fazer, as teorias pedagógicas, os movimentos sociais, as diretrizes governamentais, as políticas públicas, as representações sociais, etc. A constatação do caráter mundial dessas transformações foi exposta pela Organização das Nações Unidas para a Educação, a Ciência e a Cultura (UNESCO), com destaque para os estudos de Philip H. Coombs (1976), Relatório Edgard Faure (1972) e Relatório Jacques Delors (1996), bem como o reconhecimento de vários países, industrializados ou não, que indicavam a educação básica como um dos maiores desafios para o desenvolvimento humano, social e econômico. Em comunicado conjunto de 2013, agências das Nações Unidas ${ }^{12}$ reportaram-se

12 Comunicado firmado por Irina Bokova/Diretora-Geral-UNESCO, Guy Ryder/Diretor-Geral-Organização Internacional do Trabalho (OIT), Anthony Lake/Diretor-Executivo-Fundo 
também à existência de uma "crise da aprendizagem" e destacaram os professores como "a solução principal" para o seu enfrentamento. Nesse comunicado, constatou-se a postura diferenciada de alguns países em "melhorar o status dos professores" $"$, entre os quais as agências situam o Brasil ${ }^{14}$.

A atenção, mundialmente colocada, sobre a educação decorre do crescente reconhecimento do seu potencial de impacto sobre as sociedades contemporâneas, embora essa relação não se dê de modo direto ou linear. O que se observa é que em sociedades com características emancipatórias, nas quais são garantidas condições sociais de desenvolvimento, a educação constitui um forte elemento de inclusão social e de incorporação de tecnologias e conhecimentos, enquanto que, nas sociedades em que tais condições não são asseguradas, a educação tende a reforçar ou reproduzir as desigualdades sociais.

\section{Conclusões}

A trajetória da institucionalização dos MPE contribui para identificar elementos que podem sinalizar novas perspectivas para a pós-graduação profissional stricto sensu, no cenário brasileiro. As conclusões a que chegamos aportam indicações muito sugestivas do avanço e consolidação desse processo na área da Educação; mas, confirmam, também, a importância em continuar desenvolvendo estudos e monitorando os processos e as políticas voltadas para a área.

das Nações Unidas para a Infância (UNICEF), Helen Clark-Administrador-Programa das Nações Unidas para o Desenvolvimento (PNUD) e Fred van Leeuwen-Secretário-Geral/Education International. Disponível em: <http://www.unesco.org/new/fileadmin/MULTIMEDIA/HQ/ED/pdf/05-10jointMessage-wtd2013-en.pdf>. Acesso em: 03 ago. 2016.

13 Essa melhoria refere-se a "[...] programas de profissionalização e certificação, incentivos para o trabalho em comunidades remotas e desfavorecidas, leis de salários-mínimos, modelos de desenvolvimento de carreira, desenvolvimento profissional continuado, apoio a professoras escaladas para trabalhar em localidades remotas, apoio entre os próprios professores e tutoria intergeracional, prêmios de reconhecimento e incentivo à progressão de profissional, aumento dos padrões de admissão nos programas de treinamento, campanhas de conscientização pública, cursos gratuitos e bônus de recrutamento". Disponível em: $<$ http://www.unesco.org/new/pt/brasilia/ about-this-office/single-view/news/world_teachers_day_5_october_2013_a_joint_message/\#.VP4-LfnF-AU>. Acesso em: 03 ago. 2016.

14 Registramos que o Brasil foi considerado, por pesquisa recente, o penúltimo país do mundo que mais desrespeita o professor, depois de Israel. A pesquisa - Global Teacher Status Index - foi desenvolvida pela Fundação Varkey GEMS e divulgada em outubro de 2013, mesma época em que a Unesco divulgou os dados sobre o panorama mundial da educação básica. Disponível em: $<$ https://www.varkeygemsfoundation.org/sites/default/files/documents/2013GlobalTeacherStatusI ndex.pdf>. Acesso em: 03 ago. 2016. 
Dentre os aspectos observados, constatamos que o processo se desenvolve de modo lento e, por vezes, desordenado, a despeito de demonstrar períodos de intensa produção de referências legais e ou acadêmicas; por outro lado, o volume de informações e conhecimentos hoje disponível no sistema da pós-graduação e no âmbito da academia (aqui brevemente referido) confere amplas condições de aprofundamento sobre variados temas, maior precisão e segurança nas decisões relativas às políticas da área da Educação. No caso específico da formação pós-graduada profissional stricto sensu, há de se registrar que, a despeito dessa trajetória, ela é ainda inconclusa, posto inexistir, até então, doutorados profissionais implantados, quaisquer que sejam as áreas de conhecimento.

Como novas perspectivas da pós-graduação profissional em Educação, no Brasil, destacamos: (a) a própria institucionalização dos MPE, que indica fortalecimento da sua base epistêmica, ao contemplar relações entre educação superior e educação básica, mundo acadêmico e setor produtivo, setor público e setor privado, educação e formação de trabalhadores, das mais diversas práticas sociais; (b) mudanças no panorama da oferta da pós-graduação em Educação com a emergência da nova configuração trazida pelos MPE, com potencial de qualificação dos sistemas de ensino e outros ambientes profissionais; e (c) o trato de problemáticas educacionais inerentes aos ambientes profissionais como parte integrante dos processos formativos, de pesquisa e desenvolvimento de produtos voltados para o uso, geração e experimentação de materiais, técnicas, processos, projetos, metodologias, aplicativos, etc.

Os MPE dirigem o foco aos processos formativos e de investigação para o trato de problemáticas relativas ao ambiente profissional dos pós-graduandos e ao desenvolvimento de produtos que visem soluções e ou encaminhamentos e ou intervenções no âmbito das problemáticas apresentadas. Por estarem voltados para o uso, geração e experimentação de materiais, técnicas, processos, projetos, metodologias, aplicativos, etc., os MPE são, no interior da própria área da Educação, um espaço importante de aplicação, de desenvolvimento, de avaliação e de inovação, no âmbito dos processos formativos e de investigação, do próprio campo da educação, assim como de quaisquer áreas profissionais. Esses são aspectos que também introduzem novas perspectivas na pós-graduação da Educação.

\section{REFERÊNCIAS}

BARROS, E. C.; VALENTIM, M. C.; MELO, M. A. A. O debate sobre o mestrado profissional na Capes: trajetória e definições. Revista Brasileira de Pós-Graduação, v. 
2, n. 4, p. 124-138, jul. 2005. Disponível em: <http://ojs.rbpg.capes.gov.br/index.php/ rbpg/article/view/84>. Acesso em: 12 set. 2016.

BRASIL. Conselho Federal de Educação (CFE). Câmara de Educação Superior (SESU). Parecer, $n$. 977, de 03 de dezembro de 1965. Do pronunciamento da CESU/CFE em resposta à solicitação do Ministro de Educação para definição da natureza dos cursos de pós-graduação e regulamentação do disposto na letra b do art. 69 da Lei de Diretrizes e Bases. Brasília, 1995. Disponível em: <https://www.capes.gov.br/images/stories/download/legislacao/Parecer_CESU_977_1965.pdf>. Acesso em: 06 set. 2016.

COOMBS, P. H. A crise mundial da educação. São Paulo: Editora Perspectiva, 1976. (Série Debates 112 - Educação).

COORDENAÇÃO DE APERFEIÇOAMENTO DE PESSOAL DE NÍVEL SUPERIOR. CAPES. Portaria $n^{\circ}$ 47, de 17 de outubro de 1995. Disponível em: <http://ojs.rbpg.capes. gov.br/index.php/rbpg/article/view/87/83>. Acesso em: 06 ago. 2016.

COORDENAÇÃO DE APERFEIÇOAMENTO DE PESSOAL DE NÍVEL SUPERIOR. CAPES. Portaria $n^{\circ} 80$, de 16 de dezembro de 1998. Dispõe sobre o reconhecimento dos mestrados profissionais e dá outras providências. Disponível em: $<$ https://www.capes.gov. br/images/stories/download/avaliacao/avaliacao-n/1892015-Portaria-CAPES-080-1998. pdf>. Acesso em: 06 ago. 2016.

COORDENAÇÃO DE APERFEIÇOAMENTO DE PESSOAL DE NÍVEL SUPERIOR. CAPES. Plataforma Sucupira. Dados Quantitativos de Programas Recomendados e Reconhecidos. Área de Avaliação. Área de Conhecimento. Educação. 2010. Disponível em: <https://sucupira.capes.gov.br/sucupira/public/consultas/coleta/programa/quantitativos/quantitativoAreaConhecimento.jsf?areaAvaliacao=38>. Acesso em: 12 set. 2016 .

COORDENAÇÃO DE APERFEIÇOAMENTO DE PESSOAL DE NÍVEL SUPERIOR. CAPES. Portaria $n^{\circ} 81$, de 03 de junho de 2016. Define as categorias de docentes que compõem os Programas de Pós-Graduação (PPGs) stricto-sensu. Disponível em: $<$ http:// www.capes.gov.br/images/stories/download/legislacao/06062016-PORTARIA-N-8-De-3-DE-JUNHO-DE-2016.pdf>. Acesso em: 06 ago. 2016.

DELORS, J. Educação um tesouro a descobrir. Relatório para a UNESCO da Comissão Internacional sobre Educação para o século XXI. São Paulo: Cortez Editora; Brasília: UNESCO, 1996.

FARIA FILHO, L. M. O novo PNPG e a educação básica. Educação em Revista, Belo Horizonte, v. 29, n. 2, p. 289-295, jun. 2013. Disponível em: <http://www.scielo.br/pdf/ edur/v29n2/13.pdf>. Acesso em: 15 set. 2016.

FAURE, E. Aprender a ser. São Paulo: Livraria Bertrand, 1972.

FÁVERO, O. Pós-graduação em Educação: avaliação e perspectivas. Revista de Educação Pública, [S.1.], v. 18, n. 37, p. 311-327, set. 2012. Disponível em: $<$ http://periodicoscientificos.ufmt.br/ojs/index.php/educacaopublica/article/view/482>. Acesso em: 15 set. 2016. 
FÓRUM DE COORDENADORES DE PROGRAMAS DE PÓS-GRADUAÇÃO EM EDUCAÇÃO. (FORPRED). Documento 2. Documento da Comissão do FORPRED para subsidiar a discussão sobre Mestrado Profissional para a Área de Educação da CAPES. Brasília, mar. 2012. Disponível em: < https://www.fe.unicamp.br/seminario-fe/2013/ GT2-Doc-MestradoProfissional.pdf $>$. Acesso em: 12 set. 2016.

GATTI, B.; ANDRÉ, M.; FÁVERO, O.; CANDAU, V. M. F. O modelo de avaliação da CAPES. Revista Brasileira de Educação, Rio de Janeiro, n. 22, p. 137-144, abr. 2003. Disponível em: $<$ http://www.scielo.br/pdf/rbedu/n22/n22a12.pdf $>$. Acesso em: 13 out. 2016.

HETKOWSKI, T. M.; FIALHO, N. H.; SACRAMENTO, J. A. Mestrado profissional em educação: gestão e tecnologias aplicadas à educação. Educação em Perspectiva, Viçosa, v. 4, n. 2, p. 489-509, jul./dez. 2013. Disponível em: <http://www.seer.ufv.br/ seer/educacaoemperspectiva/index.php/ppgeufv/article/viewFile/429/122>. Acesso em: 03 ago. 2016.

HORTA, J. S. B.; MORAES, M. C. M. O sistema CAPES de avaliação da pós-graduação: da área de educação à grande área de ciências humanas. Revista Brasileira de Educação, n. 30, p. 95-181, set./out./nov./dez. 2005. Disponível em: <http://www.scielo.br/pdf/ rbedu/n30/a08n30.pdf $>$. Acesso em: 12 set. 2016.

HOSTINS, R. C. L. Os Planos Nacionais de Pós-graduação (PNPG) e suas repercussões na pós-graduação brasileira. Perspectiva, Florianópolis, v. 24, n. 1, p. 133-160, jan.jun. 2006.

INFOCAPES. Capes - a necessidade de desenvolvimento da pós-graduação profissional e o ajustamento do sistema de avaliação às características desse segmento. Boletim Informativo da CAPES, Brasília: CAPES, v. 10, n. 1, p. 1-189, jan./mar. 2002.

INSTITUTO NACIONAL DE ESTUDOS E PESQUISAS EDUCACIONAIS ANÍSIO TEIXEIRA. (INEP). Dados do Ideb 2015 já estão disponiveis para consulta. Disponível em: <http://portal.inep.gov.br/visualizar/-/asset_publisher/6AhJ/content/dados-do-ideb-2015-ja-estao-disponiveis-para-consulta>. Acesso em: 12 set. 2016.

KUENZER, A. Z.; MORAES, M. C. M. Temas e tramas na pós-graduação em educação. Educação e sociedade, Campinas, v. 26, n. 93, p. 1341-1363, set./dez. 2005. Disponível em: <http://www.scielo.br/pdf/es/v26n93/27284.pdf >. Acesso em: 06 set. 2016.

MORAES, M. C. M. Paradigmas e adesões: temas para pensar a teoria e a prática em educação. Revista Perspectiva, Florianópolis, NUP/CED/UFSC, ano 17, n. 32, p. 5168, 1999 .

MORAES, M. C. M. Avaliação na pós-graduação brasileira: novos paradigmas, antigas controvérsias. In: BIANCHETTI, L.; MACHADO, A. M. N. M. (Org.). A bússola do escrever: desafios e estratégias na orientação de teses e dissertações. São Paulo: Cortez; Florianópolis: Editora da UFSC, 2002. p. 187-214.

MOREIRA, C. O. F.; HORTALE, V. A.; HARTZ, Z. A. Avaliação da pós-graduação: buscando consenso. Revista Brasileira de Pós-graduação, Brasília: RBPG, v. 1, n. 1, p. 26-40, 2004. 
NEVES, A. B. Metas da atual gestão para a Capes. INFOCAPES, Brasília: CAPES, n. 1 e 2, v. 3, 2005. Disponível em: <https://www.capes.gov.br/images/stories/download/ bolsas/INF1E295.pdf>. Acesso em: 15 set. 2016.

PLANO NACIONAL DE PÓS-GRADUAÇÃO. (PNPG 2011-2020). Brasília: CAPES, 2010. 2. v. Disponível em: <https://www.capes.gov.br/images/stories/download/Livros-PNPG-Volume-I-Mont.pdf>; <https:/www.capes.gov.br/images/stories/download/ PNPG_Miolo_V2.pdf>. Acesso em: 12 ago. 2016.

PLANO NACIONAL DE EDUCAÇÃO. (PNE). Lei no 13.005, de 25 de junho de 2014. Aprova o Plano Nacional de Educação - PNE e dá outras providências. Disponível em: $<$ http://www.planalto.gov.br/ccivil_03/_ato2011-2014/2014/lei/113005.htm>. Acesso em: 12 set. 2016.

REVISTA BRASILEIRA DE PÓS-GRADUAÇÃO. Mestrado no Brasil - a situação e uma nova perspectiva. Brasília: RBPG, v. 2, n. 4, p. 139-144, jul. 2005. Disponível em: <http://ojs.rbpg.capes.gov.br/index.php/rbpg/article/view/85/81>. Acesso em: 12 set. 2016.

REVISTA BRASILEIRA DE PÓS-GRADUAÇÃO. Parâmetros para análise de projetos de mestrado profissional 2002. Brasília: RBPG, v. 2, n. 4, p. 156-161, jul. 2005. Disponível em: <http://ojs.rbpg.capes.gov.br/index.php/rbpg/article/viewFile/90/86>. Acesso em: 12 set. 2016.

REVISTA BRASILEIRA DE PÓS-GRADUAÇÃO. Programa de Flexibilização do Modelo de Pós-Graduação Senso Estrito em Nível de Mestrado 1995. Brasília: RBPG, v. 2, n. 4, p. 145-146, jul. 2005. Disponível em: <http://ojs.rbpg.capes.gov.br/index.php/ rbpg/article/view/86/82>. Acesso em: 06 set. 2016.

SANTOS, M.; SILVEIRA, M. L. O ensino superior público e particular e o território brasileiro. Brasília, 2000.

SANTOS, M.; SILVEIRA, M. L. O Brasil: território e sociedade no início do século XXI. Rio de Janeiro: Record, 2001.

SPAGNOLO, F.; SOUZA, V. C. O que mudar na avaliação da Capes? Revista Brasileira de Pós-Graduação, v. 1, n. 2, p. 8-34, nov. 2004. Disponível em: <http://ojs.rbpg.capes. gov.br/index.php/rbpg/article/viewFile/38/35>. Acesso em: 15 set. 2016.

WASSEM, J. Avaliação de programas de pós-graduação de excelência em Educação: desenho de uma pesquisa. In: EDUCERE - CONGRESSO NACIONAL DE EDUCAÇÃO, XII.; SEMINÁRIO INTERNACIONAL DE REPRESENTAÇÕES SOCIAIS, SUBJETIVIDADE E EDUCAÇÃO - SIRSSE, III.; SEMINÁRIO INTERNACIONAL SOBRE PROFISSIONALIZAÇÃO DOCENTE (SIPD/CÁTEDRA UNESCO), V.; ENCONTRO NACIONAL SOBRE ATENDIMENTO ESCOLAR HOSPITALAR ENAEH - "FORMAÇÃO DE PROFESSORES, COMPLEXIDADE E TRABALHO DOCENTE”, IX., 2015, Curitiba. Anais... Curitiba: PUC-PR, 26 a 29 de outubro de 2015. Disponível em: <http://docplayer.com.br/10853263-Avaliacao-de-programas- 
FIALHO, N. H.; HETKOWSKI, T. M. Mestrados Profissionais em Educação: novas perspectivas...

-de-pos-graduacao-de-excelencia-em-educacao-desenho-de-uma-pesquisa.html; http:// educere.pucpr.br/>. Acesso em: 15 set. 2016.

Texto recebido em 03 de outubro de 2016. Texto aprovado em 04 de novembro de 2016. 